\title{
Territorios de las metodologías artísticas de investigación con un fotoensayo a partir de Buñuel
}

Territórios das metodologias artísticas de investigação com um foto-ensaio a partir de Buñuel

Territories of the art-based research methodologies with a photo-essay from Buñuel

\author{
Ricardo Marín-Viadel \\ ricardom@ugr.es \\ Universidad de Granada/ Facultad de Bellas Artes
}

\section{Joaquín Roldán}

joaquinroldan@ugr.es

Universidad de Granada / Facultad de Educación

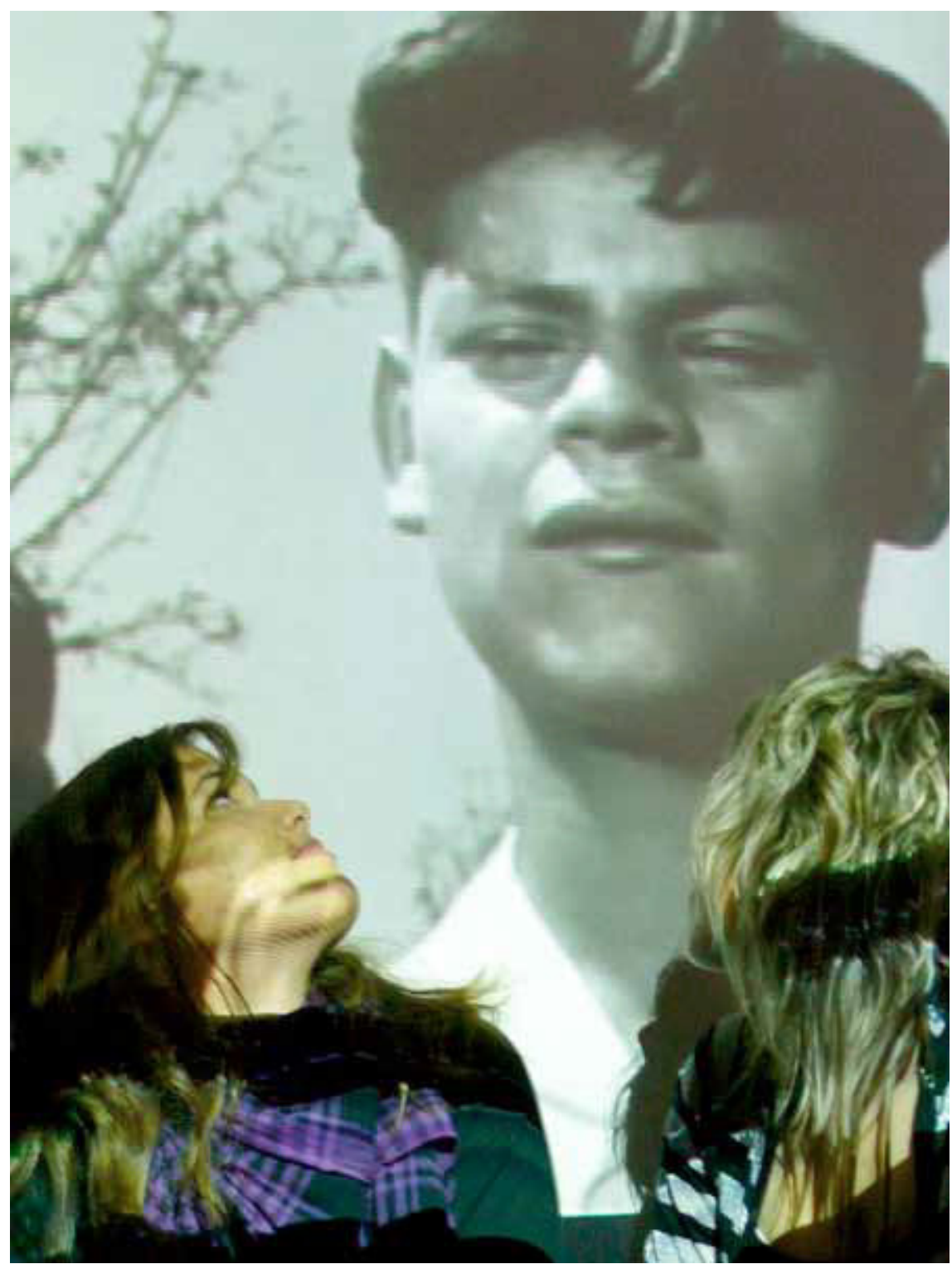

Fig.1. Foto-Resumen. Autores. Aprendiendo de Buñuel I (2008). Fotografía digital con una cita visual indirecta. (Dancigers \& Buñuel, 1950). 


\section{RESUMEN}

La Investigación basada en las Artes (Arts based Research) usa Metodologías Artísticas de Investigación (MAI) que se basan en las formas de indagación que utilizan los profesionales de la literatura, las artes visuales, la música, el teatro, la danza, etc. El rasgo distintivo de las MAl es que el informe final de investigación puede consistir fundamentalmente en un poema, un relato de ficción, un grupo de dibujos o pinturas, una canción, una coreografía o una película. El objetivo principal de las MAI es mejorar el conocimiento de los fenómenos y acontecimientos humanos mediante procesos de indagación, formas de comunicación y sistemas de representación que pongan el énfasis en las cualidades artísticas y estéticas tanto del desarrollo y como de los resultados finales de la investigación. En un Cuadro Descriptivos presentamos los manuales universitarios, revistas profesionales, grupos de investigación y asociaciones profesionales más relevantes en investigación en Educación Artística, en el contexto de la investigación en Humanidades y en Artes Visuales. Un fotoensayo explica los procesos artísticos de enseñanza y aprendizaje, a partir de la película Los olvidados de Buñuel, con nuestro alumnado de magisterio sobre cómo el cine representa la violencia y la escuela.

Palabras-clave: Metodologías Artísticas de Investigación, Fotoensayo, Investigación en Artes, Investigación Educativa basada en las Artes Visuales

\section{RESUMO}

A pesquisa baseada na Artes (Arts based-Research) usa Metodologias de Pesquisa Artística (MPA), com base nas formas de investigação utilizadas pela literatura, artes visuais, música, teatro, a dança, etc. A característica distintiva do MPA é que o relatório final de pesquisa pode ser constituído, essencialmente, por um poema, uma história fictícia, um grupo de desenhos ou pinturas, uma canção, uma dança ou um filme. O objetivo principal do MPA é melhorar o conhecimento dos fenómenos e eventos humanos através de processos de pesquisa, das formas de comunicação e sistemas de representação que colocam a ênfase em qualidades artísticas e estéticas tanto do desenvolvimento como dos resultados finais da pesquisa. Num quadro descritivo apresentamos livros académicos, revistas profissionais, grupos de investigação, associações profissionais relevantes na área da Educação Artística, no contexto da investigação nas Humanidades e nas Artes Visuais. Um ensaio fotográfico explica os processos artísticos de ensino e aprendizagem com os nossos alunos de magistério (formação inicial de professores) 
sobre como o cinema representa a violência e a escola, a partir do filme Los Olvidados de Buñuel.

Palavras-chave: Metodologias de Pesquisa Artística, ensaio fotográfico, Pesquisa em Artes, Pesquisa Educacional baseada em Artes Visuais

\section{ABSTRACT}

Arts based Research (Investigación basada en Artes, in Spanish) uses Artistic Research Methodologies (ARM), which are founded in the forms of inquiry used by professional in literature, visual arts, music, theatre, dance, etc. The main distinctive feature of the ARM is that the final investigation report may consist, essentially, in a poem, a fictional story, a group of drawings or paintings, a song, a dance or a movie. The ARM main objective is to improve the knowledge of phenomena and human events through processes of inquiry, forms of communication and representation systems that put the emphasis on artistic and aesthetic qualities of both, the process and the final results of the research. A descriptive table show the recent and most relevant university textbooks, professional journals, research groups and professional associations about Research in Art Education, in the general context of Research in Humanities and Research in Visual Arts. A Photo essay explains the artistic processes of teaching and learning, after the film Los olvidados [The Young and the Damned in U.S.A.] by Buñuel, with our primary teacher's training students on how film represents violence and school.

Keywords: Arts based Research, Photoessay, Research in Arts, Visual Arts based Educational Research 


\section{INTRODUCCIÓN}

Este artículo está organizado en dos partes complementarias que se desarrollan en paralelo: una parte escrita, en la que se propone un cuadro descriptivo del territorio de las Metodologías Artísticas de Investigación en Educación Artística; y otra parte visual que muestra un fotoensayo que explica cómo hemos trabajado el tema del cine y la educación en la Facultad de Ciencias de la Educación de la Universidad de Granada (España) con alumnado de las titulaciones de Maestro.

Las Metodologías Artísticas de Investigación (MAI) son una nueva modalidad metodológica de hacer investigación que se basa, o se informa o se inspira, en las formas de indagación que utilizan los profesionales de la literatura, las artes visuales, la música, el teatro, la danza, etc. Se trata de emplear los modos y sistemas de trabajo profesional y las formas de (re)presentación de los datos y resultados de las diversas disciplinas artísticas en los proyectos y en los informes de investigación en ciencias humanas y sociales, y en particular en Educación Artística. El rasgo distintivo más llamativo de este tipo de metodologías de investigación es que el informe final de investigación incorpora o puede consistir fundamentalmente en un poema, un diálogo dramático, un relato de ficción, un grupo de dibujos o de pinturas, una canción, una coreografía, una película cinematográfica, un objeto, una instalación, o una escultura. Todos estos productos, propios del trabajo de creación artística, no se consideraba ni se admitía (hasta ahora) que pudieran ser una investigación propiamente dicha.

El objetivo principal de las Metodologías Artísticas de Investigación es mejorar el conocimiento de los fenómenos y acontecimientos humanos mediante procesos de indagación, formas de comunicación y sistemas de representación alternativos a los que definen a las Metodologías Cuantitativas y Cualitativas, básicamente por el énfasis que se hace en las cualidades artísticas y estéticas del desarrollo de la investigación y del propio informe o resultado final de la investigación.

Las Metodologías Artísticas de Investigación subrayan las dimensiones connotativas e imaginativas de un texto o de una imagen visual frente a la estricta denotación o a la pura referencialidad y aceptan las resonancias metafóricas para ampliar el significado literal.

Se espera que las Metodologías Artísticas de Investigación sean capaces de proponer nuevas preguntas sobre el aprendizaje y la enseñanza y sobre el aprendizaje artístico, que revelen aspectos y faceta de los problemas que pasaban inadvertidas con otros enfoques metodológicos, y consigan ampliar en extensión y profundidad los debates e ideas sobre las prácticas de enseñanza y las políticas educativas.

\section{UN CUADRO DESCRIPTIVO DE ALGUNOS TERRITORIOS METODOLÓGICOS Y DISCIPLINARES RELACIONADOS CON LAS METODOLOGÍAS ARTÍSTICAS}

En el cuadro de las páginas siguientes proponemos un esquema que presenta algunos datos relevantes sobre varios acontecimientos recientes en el amplio panorama de las metodologías de investigación en ciencias humanas y sociales, educación, educación artística y artes visuales. El reunir todos esos territorios en un mismo cuadro obedece a una razón: para muchas de las investigaciones que se hacen en Educación Artística, particularmente las que tratan asuntos visuales y desean usar Metodologías Artísticas, es necesario tener en cuenta lo qué está actualmente desarrollándose en todas estas zonas.

El cuadro está organizado en cinco columnas: tres en la mitad izquierda con territorios metodológicos y dos columnas en la mitad derecha sobre los territorios de las Metodologías Artísticas de Investigación y sobre la Investigación en Artes Visuales. Es patente la heterogeneidad de estas columnas, porque tres de ellas presentan campos del conocimiento (ciencias humanas y sociales, educación artística y artes visuales) y dos muestran modalidades metodológicas: las metodologías visuales por un lado y las metodologías artísticas por otro.

Las Metodologías Visuales no tienen porqué adoptar un enfoque artístico, sino que pueden producir tipos de imágenes habitualmente no reconocidos ni considerados como artísticos (fotografías y películas estrictamente documentales, mapas, etc.); o bien analizar y explicar imágenes visuales a través de un discurso verbal que no es ni pretende ser un texto literario. Las Metodologías Artísticas pueden discur- 


\begin{tabular}{|c|c|c|c|c|c|}
\hline \multicolumn{6}{|c|}{$\begin{array}{l}\text { Cuadro orientativo de las Metodologías de Investigación e } \\
\qquad \text { en el contexto de las Humanidades }\end{array}$} \\
\hline \multicolumn{2}{|c|}{$\begin{array}{l}\text { Metodologías de Investigación } \\
\text { en Ciencias Humanas y Sociales en general } \\
\text { y en Educación en particular }\end{array}$} & \multirow{2}{*}{\multicolumn{2}{|c|}{$\begin{array}{c}\begin{array}{c}\text { Metodologías de Investigación } \\
\text { en EDUCACIÓN ARTísTICA } \\
\text { (Art Education Research) }\end{array} \\
\text { Metodologías para investigar una zona especí- } \\
\text { fica de los problemas humanos: el aprendizaje } \\
\text { de las artes y culturas visuales. }\end{array}$}} & \multicolumn{2}{|c|}{$\begin{array}{l}\text { Metodologías VISUALES de Investigación } \\
\text { en Ciencias Humanas y Sociales } \\
\text { (Visual Methodologies) }\end{array}$} \\
\hline \multicolumn{2}{|c|}{$\begin{array}{l}\text { Metodologías para investigar los problemas } \\
\text { humanos y sociales, especialmente los educativos. }\end{array}$} & & & \multicolumn{2}{|c|}{$\begin{array}{l}\text { Métodologías que trabajan principalmente } \\
\text { produciendo o interpretando imágenes visua- } \\
\text { les, para investigar los problemas humanos. }\end{array}$} \\
\hline $\begin{array}{l}\text { Enfoques generales y } \\
\text { Metodologiás } \\
\text { Cuantitativas }\end{array}$ & $\begin{array}{l}\text { Metodologías } \\
\text { Cualitativas }\end{array}$ & $\begin{array}{l}\text { Sistema educativo } \\
\text { formal }\end{array}$ & $\begin{array}{l}\text { Otras zonas de } \\
\text { aprendizaje }\end{array}$ & $\begin{array}{l}\text { PRODUCE } \\
\text { imágenes }\end{array}$ & $\begin{array}{l}\text { INTERPRETA } \\
\text { imágenes }\end{array}$ \\
\hline \multicolumn{6}{|c|}{ selección de MANUALES universitarios } \\
\hline \multirow{2}{*}{$\begin{array}{l}\text { COHEN, L.; MANION, L.; } \\
\text { MORRISON, K. (2011) } \\
\text { KELLY, A. E.; LESH R.A.; } \\
\text { BAEK, J. Y. (2008) }\end{array}$} & \multirow[b]{2}{*}{$\begin{array}{l}\text { DENZIN, N. K.; LINCOLN, } \\
\text { Y. S. (Eds.): (2000) }\end{array}$} & \multirow{2}{*}{\multicolumn{2}{|c|}{$\begin{array}{l}\text { BRESLER, L. (ed.) (2007); } \\
\text { EISNER, E. W.; DAY, M. D.: (2004); } \\
\text { HICKMAN, R. (ed.) (2008); } \\
\text { LAPIERRE, S. D.; ZIMMERMAN, E. (Eds.) (1997); } \\
\text { MARIN-VIADEL, R. (coord.) (2005); }\end{array}$}} & $\begin{array}{l}\text { COLLIER, J. Jr.: (1967); } \\
\text { PROSSER, J. (Ed.): (1998); }\end{array}$ & $\begin{array}{l}\text { PINK, S. (2001); } \\
\text { ROSE, G. (2007). }\end{array}$ \\
\hline & & & & \multicolumn{2}{|c|}{$\begin{array}{l}\text { BANKS, M. (2001); DE LANGE, N., MITCHELL, C. } \\
\text { \& STUART, J. (eds.) (2007); HAMILTON, P. (ed.) } \\
\text { (2006); KNOWLES, C.; SWEETMAN, P. (eds.) } \\
\text { (2004); STANCZAK, G. C. (2007). }\end{array}$} \\
\hline \multicolumn{6}{|c|}{ selección de REVISTAS de investigación } \\
\hline $\begin{array}{l}\text {-Cognitive Psichology. } \\
\text {-Educational Researcher. } \\
\text { - Emotion. }\end{array}$ & $\begin{array}{l}\text {-International Journal of } \\
\text { Qualitative Methods } \\
\text {-International Journal } \\
\text { of Qualitative Studies in } \\
\text { Education } \\
\text {-Qualitative Inquiry }\end{array}$ & $\begin{array}{l}\text {-Arte, individuo y sociedad. } \\
\text {-International Journal of Art } \\
\text { and Design Education. } \\
\text {-International Journal of } \\
\text { Education \& the Arts. } \\
\text {-International Journal of } \\
\text { Education Through art. } \\
\text {-Journal of Aesthetic } \\
\text { Education. } \\
\text { - Studies in Art Education. } \\
\text {-Visual Arts Research. } \\
\text { - InVisibilidades. }\end{array}$ & $\begin{array}{l}\text { - Art Therapy } \\
\text {-Arteterapia } \\
\text {-Journal of } \\
\text { Arts \& Com- } \\
\text { munities. }\end{array}$ & \multicolumn{2}{|c|}{$\begin{array}{l}\text { - Visual Anthropology } \\
\text { - Visual Anthropology Review } \\
\text { - Visual studies } \\
\text { - www.visualsociology.org }\end{array}$} \\
\hline \multicolumn{6}{|c|}{ Denominación de algunos de los enfoques Metodológicos más frecuentes } \\
\hline $\begin{array}{l}\text { Históricos } \\
\text { Descriptivos: } \\
\text { - demográficos } \\
\text { - correlacionales } \\
\text {-longitudinales } \\
\text {-transversales } \\
\text {-restrospectivos } \\
\text { Encuestas (Survey) } \\
\text { Comparativos } \\
\text { Experimentales: } \\
\text { - Pre-trest/post-test }\end{array}$ & $\begin{array}{c}\text { Estudios de casos } \\
\text { Estudios culturales } \\
\text { Etnografía crítica } \\
\text { Autoetnografía } \\
\text { Feministas } \\
\text { Fenomemología } \\
\text { Hermenéutica } \\
\text { Historias de vida } \\
\text { Investigación-Acción } \\
\text { Narrativa } \\
\text { Performativa } \\
\text { Postcolonial } \\
\text { Postestructuralistas }\end{array}$ & \multicolumn{2}{|c|}{$\begin{array}{l}\text { Se usan habitualmente los mismos que en } \\
\text { Ciencias Humanas y Sociales en general. } \\
\text { Algunas estrategias metodológicas que han } \\
\text { surgido en Educatión Artística apenas si se han } \\
\text { desarrollado fuera de este campo, tales como: } \\
\text {-Crítica educativa (Educational Criticism) } \\
\text {-Expertización educativa (educational con- } \\
\text { noisseurship). }\end{array}$} & $\begin{array}{l}\text {-Image based } \\
\text { Educational Research }\end{array}$ & $\begin{array}{l}\text {-análisis de contenido } \\
\text {-semiología } \\
\text {-deconstrucción } \\
\text {-psicoanálisis }\end{array}$ \\
\hline \multicolumn{6}{|c|}{ selección de algunas ASOCIACIONES Profesionales de Investigación y bases de datos } \\
\hline \multicolumn{2}{|c|}{$\begin{array}{l}\text { AERA. American Educational Research Association. } \\
\text { ERIC. Educational Resources Information Centre. }\end{array}$} & $\begin{array}{l}\text { INSEA. International Society } \\
\text { for Education Through Art. } \\
\text { NAEA. National Art Education } \\
\text { Association. }\end{array}$ & $\begin{array}{l}\text { AATA Ameri- } \\
\text { can Art The- } \\
\text { rapy Associa- } \\
\text { tion. }\end{array}$ & \multicolumn{2}{|c|}{$\begin{array}{l}\text { IVSA. International Visual Sociology Association. } \\
\text { www.societyforvisualanthropology.org }\end{array}$} \\
\hline
\end{tabular}


rir por territorios visuales, pero también por otros muchos más: musicales, teatrales, poéticos, etc. La intersección entre las Metodologías Visuales y las Metodologías Artísticas es la zona que corresponde a las Metodologías Artísticas basadas en las Artes Visuales (Visual Arts based Research) que pueden usarse para trabajar problemas muy diversos, y también sobre temas educativos, en cuyo caso se denominarían Metodologías de Investigación Educativa basadas en las Artes Visuales (Visual Arts based Educational Research). Las Metodologías de Investigación Educativa basadas en las Artes Visuales pueden utilizarse para trabajar sobre cualquier tipo de temas educativos, y también sobre Educación Artística; en este caso se denominarían Metodologías de Investigación basadas en las Artes Visuales en Educación Artística (Visual Arts based Research in Art Education).

Las cuatro filas que atraviesan las columnas sirven para encasillar cuatro conceptos: (a) una selección de manuales universitarios sobre metodologías de investigación, (b) una relación de revistas de investigación especializadas en cada ámbito, (c) una síntesis de las denominaciones de metodologías y enfoques de investigación característicos de cada territorio y, por último, (d) una relación de asociaciones y grupos profesionales de investigación, así como de bases de datos de libre acceso.

La estructura cuadriculada que presenta el cuadro no debe inducir la idea de equivalencia entre cada una de las casillas. En el caso de la columna correspondiente a las metodologías de investigación en Ciencias Humanas y Sociales en general y en Educación en particular, y en la columna de las Metodologías Visuales de Investigación en Ciencias Humanas y Sociales (Visual Methodologies) la información que se presenta es una reducidísima síntesis de unos pocos manuales recientemente publicados, o de unas pocas revistas 0 asociaciones profesionales de gran prestigio. Mientras que en las tres columnas restantes (Educación Artística, Metodologías Artísticas de Investigación y Metodologías de Investigación en Artes Visuales) se presentan abundantes referencias, que sin llegar a ser exhaustivas, casi llegan a dar cuenta completa de los datos existentes hasta el momento en cada uno de estos territorios.
Probablemente la zona más interesante del cuadro es la parte derecha, en la que se relacionan las Metodologías Artísticas de Investigación con la Investigación en las Artes. A pesar de la similitud de sus denominaciones se trata de territorios muy diferentes. El primero corresponde a un enfoque metodológico que se está extendiendo desde las disciplinas de la Educación Artística al conjunto de las Ciencias de la Educación. El segundo se refiere a los problemas de investigación y de metodologías de investigación científica cuando se trabaja desde campos tradicionalmente etiquetados como creación artística: arquitectura, dibujo, pintura, escultura, cine, diseño, música y danza. Las Metodologías Artísticas de Investigación se están desarrollando principalmente por parte de profesores y profesoras con una formación inicial en alguna disciplina artística (literatura, bellas artes, música, etc.) y que desarrollan su actividad profesional como docentes e investigadores en facultades de educación y de formación del profesorado, muy frecuentemente en materias vinculadas a la educación artística, musical o literaria. Por su parte la Investigación en las Artes, se está elaborando por parte de profesores y profesoras con una formación inicial en alguna disciplina artística o humanística y que trabajan como docentes e investigadores en facultades de bellas artes y diseño.

También es curiosa cierta diferenciación geográfica, mientras que el principal desarrollo de las Metodologías Artísticas de Investigación se ha producido en América, la Investigación en Artes se ha desarrollado preferentemente en Europa.

En el campo de las Metodologías Artísticas de Investigación una de las personas pioneras en la elaboración de todo este proyecto metodológico es Elliot Eisner, de la Universidad de Stanford, que acaba de publicar un manual decisivo sobre los conceptos fundamentales en los que se sustenta esta propuesta. Aunque la mayoría de los manuales que se están publicando últimamente abarcan prácticamente la totalidad de las especialidades artísticas, comienza a notarse una cierta especialización en áreas diferenciadas: T. Barone de la Universidad de Tucson (Arizona) en literatura, especialmente novela y cuento; J. Saldaña de la Universidad Estatal de Arizona en etnoteatro; N. Daykin en música, etc. 

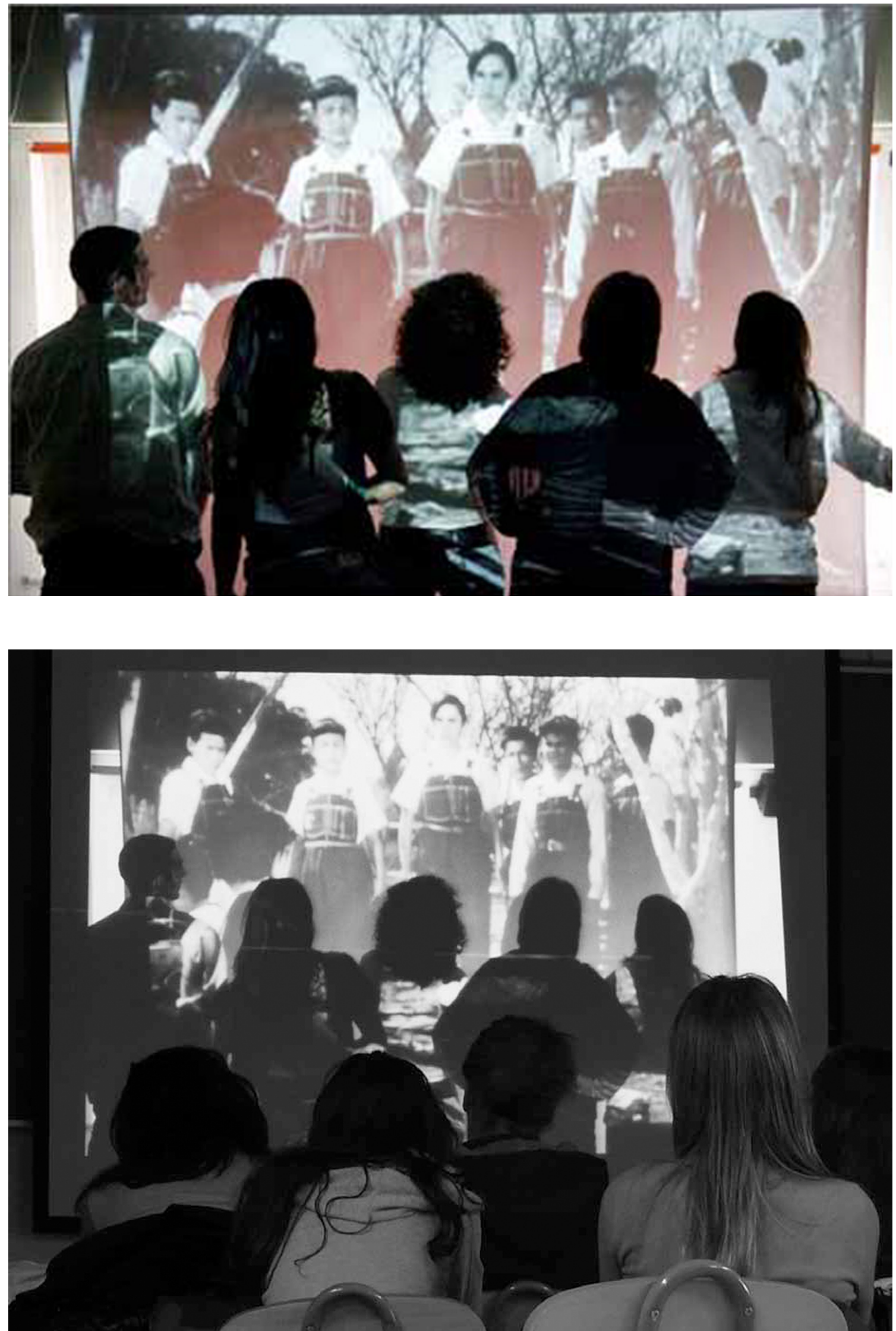

Fig.2. Autores. Aprendiendo de Buñuel II (2012) Fotoensayo compuesto por dos fotografías digitales de los autores con una cita visual indirecta. (Dancigers \& Buñuel, 1950). 
Uno de los núcleos más activos sobre el conjunto de las Metodologías Artísticas de Investigación es el grupo de interés específico ABER-SIG de la Asociación Americana de Investigación en Educación [AERA], que coordina actualmente Barbara Bickel de la Universidad del sur de Illinois Carbondale.

Mención especial merecen los grupos que trabajan en $A / r / t / o g r a f i ́ a[A / r / t o g r a p h y]$ especialmente activos en torno a Rita L. Irwin de la Universidad de la Columbia Británica en Vancouver y de S. Springgay, ahora en la Universidad de Pennsylvania, ambas en el campo de las artes visuales. Tanto por su relativamente larga tradición como por la gran elaboración de su tendencia metodológica que, en el marco de la Investigación basada en las Artes, enfatiza la necesaria simbiosis entre las actividades profesionales de la personas que son al mismo tiempo docentes, investigadoras y artistas, para construir un proceso metodológico que en lugar de disociar cada una de estas dimensiones, encuentre los territorios intermedios entre las tres.

Trabajando en metodologías de Investigación en las Artes hay varios grupos, probablemente el más prolífico en sus publicaciones es el vinculado a Michael Biggs, profesor de estética en la Facultad de Artes Creativas de la Universidad de Hertfordshire (Reino Unido), que se ha desarrollado desde hace unos once años en torno a la revista digital “Working Papers in Art and Design" (Documentos de trabajo en arte y diseño). Otro grupo, de carácter más institucional, es el 'European Artistic Research Network. EARN' (Red Europea de Investigación Artística) que se formó en 2004 entre diez facultades de bellas artes europeas para intercambiar información y experiencias sobre Investigación Artística, que ellos definen como una orientación investigadora que se fundamenta principalmente en las prácticas artísticas actuales. Un tercer grupo, gira entorno a la universidad Aalto de Helsinki, entre cuyas contribuciones destacan los libros del profesor Juha Varto, sobre fenomenología de la investigación artística.

\section{LAS METODOLOGÍAS ARTÍSTICAS DE INVESTIGACIÓN Y LAS METODOLOGÍAS ARTÍSTICAS DE ENSEÑANZA Y APRENDIZAJE}

La enseñanza y el aprendizaje de las Artes Visuales puede enfocarse desde metodologías didácticas muy diferentes.
El hecho de que los temas o los asuntos que se están trabajando en el aula, en cualquier nivel de enseñanza, sean temas artísticos no significa que necesariamente se estén utilizando Metodologías Artísticas de Enseñanza y Aprendizaje. El arte contemporáneo puede enfocarse a través de métodos pura y estrictamente transmisivos y memorísticos (por ejemplo si hay que aprender de memoria a relacionar nombres propios de artistas con denominaciones de estilos o movimientos artísticos y estos hay que saber asociarlos a imágenes de obras de arte). Las Metodologías Artísticas de Enseñanza y Aprendizaje (MAEA) son las metodologías didácticas que proponen en el aula formas y procedimientos de trabajo semejantes a los procesos de creación artística que desarrollan artistas contemporáneos. Es decir, hay una clara similitud entre el modo como un artista o grupo de artistas se plantea los problemas, busca conexiones interdisciplinares, selecciona y procesa los materiales visuales primarios, define las estrategias de elaboración visual del proyecto, y establece las cualidades de los objetos o imágenes finales que configuran el resultado; y el modo como se organiza en el aula las actividades y procesos que llevará a cabo el grupo de alumnos y alumnas. Generalmente, cuando puede establecerse esta equivalencia directa entre los modos de proceder del mundo profesional actual y los modos de proceder en el aula, puede considerarse que se están usando Metodologías Artísticas de Enseñanza y Aprendizaje.

La diferencia entre las Metodologías Artísticas de Enseñanza y Aprendizaje y las Metodologías Artísticas de Investigación radica en que las primeras buscan alcanzar un desarrollo profundo de competencias en cada una de las personas que constituyen el grupo de alumnos y alumnas; mientras que las segundas buscan alcanzar unos resultados o conclusiones útiles para el conjunto de los profesionales de la enseñanza y generalizables a diferentes problemas y contextos educativos.

Las Metodologías Artísticas de Investigación no están necesaria e irremisiblemente conectadas a las Metodologías Artísticas de Enseñanza y Aprendizaje, ni viceversa. Es posible desarrollar una investigación artística sobre el uso actual de la lección magistral (que no es una metodología artística de 

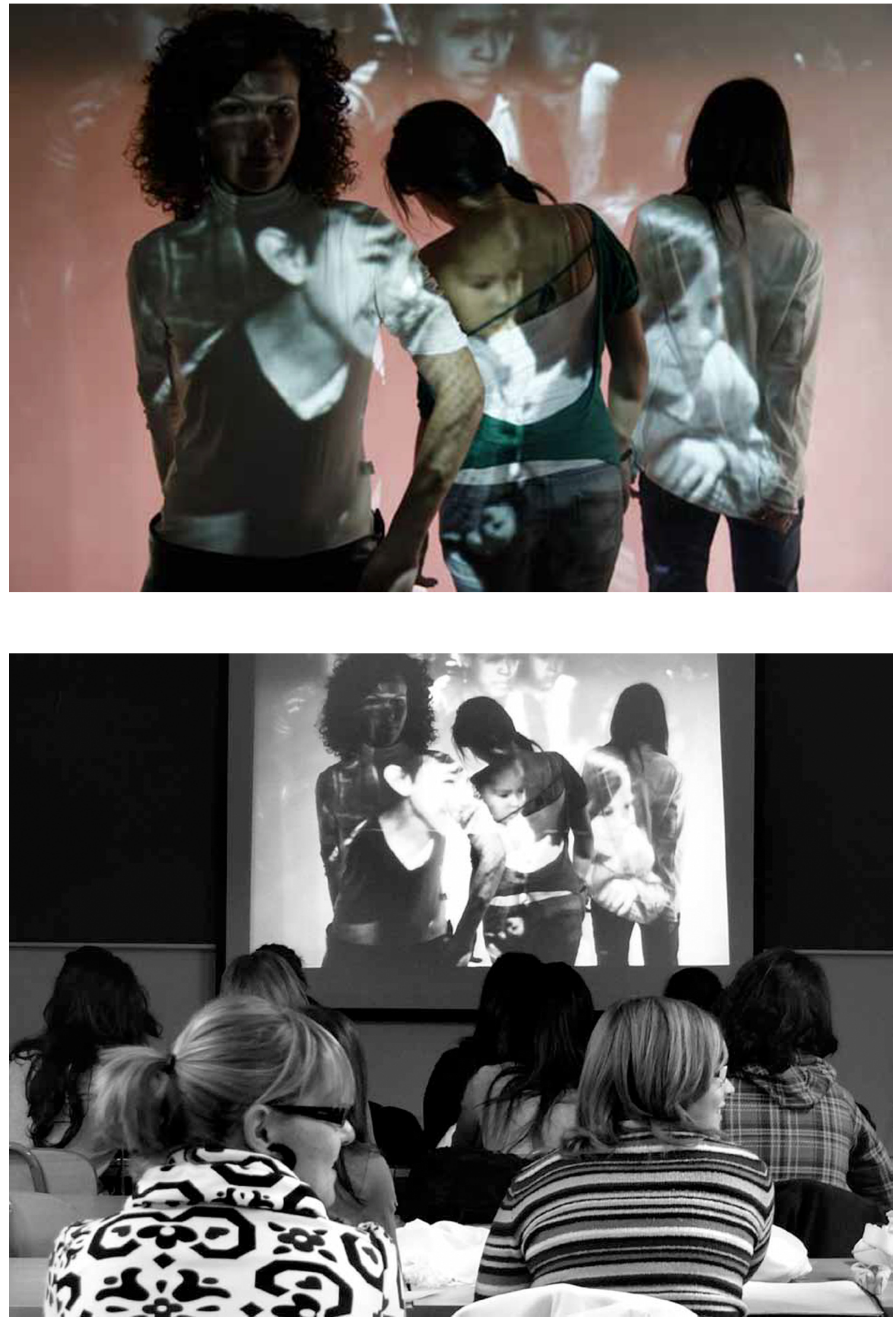

Fig.3. Autores. Aprendiendo de Buñuel III (2012) Fotoensayo compuesto por dos fotografías digitales de los autores con una cita visual indirecta. (Dancigers \& Buñuel, 1950). 
enseñanza) en las aulas universitarias; así como es posible desarrollar una investigación descriptiva correlacional sobre las variables de creatividad y razonamiento espacial (que es un enfoque cuantitativo de investigación) a partir de proyectos educativos que hayan usado Metodologías Artísticas de Enseñanza y Aprendizaje.

En la elaboración del fotoensayo que aquí presentamos hemos partido de una experiencia docente en la que hemos usado una Metodología Artística de Enseñanza y Aprendizaje con nuestro alumnado de Magisterio, y una estrategia de Investigación Fotográfica en Educación [Photography based Educational Research], que es una sub-modalidad, entre otras muchas, de Investigación Educativa basada en las Artes Visuales [Visual Arts based Educational Research]; probablemente una de las más frecuentemente utilizadas por la comodidad con la que se puede trabajar con cámaras fotográficas digitales en las aulas y por la facilidad con la que se pueden publicar fotografías en un informe de investigación.

\section{UN FOTOENSAYO A PARTIR DE LOS OLVIDADOS DE BUÑUEL}

¿Por qué y cómo trabajar el cine en la formación inicial del profesorado de educación infantil y primaria?

De entre las diferentes especialidades profesionales de las artes visuales, el cine es el que actualmente goza de mayor impacto entre la mayoría de la población; por ello trabajar a partir de imágenes cinematográficas en el aula de artes visuales es enormemente motivador y gratificante. A pesar de la gran popularidad del cine, el alumnado universitario actual, exceptuando a unos pocos cinéfilos, tiene una cultura cinematográfica que se sostiene casi exclusivamente en los grandes éxitos de las salas comerciales. Entre el alumnado de las titulaciones de Magisterio en la Universidad de Granada, apenas un dos por cien ha visto alguna de las películas del director Luis Buñuel (Calanda, 1900 - México, 1983), una de las figuras más prominentes del cine del siglo $X X$, que realizó su obra entre España, México y Francia. De entre su filmografía, el largometraje titulado Los olvidados de 1950 es la obra que de forma más directa y explícita plantea problemas educativos (Danzigers \& Buñuel, 1950).
La extraordinaria calidad de la película, la gran relevancia de su director y su temática educativa como metáfora del orden social, han sido tres razones fundamentales para trabajar esta película con el alumnado de Magisterio.

Hay muchos modos diferentes de trabajar en el aula sobre las imágenes cinematográficas. Nosotros nos propusimos reflexionar conjuntamente con nuestro alumnado de una manera eminentemente visual, sobre el tema de la representación visual de la violencia y la educación de la infancia y la adolescencia, a partir de la obra de Buñuel.

¿Por qué la fotografía digital? La decisión de trabajar fotográficamente con aparatos y técnicas digitales (muchos alumnos y muchas alumnas usan la cámara de sus teléfonos móviles), responde básicamente a tres razones: (a) nuestra convicción de que la creación de imágenes debe ser la actividad fundamental y característica del aprendizaje en las artes visuales (lo que el alumnado debe saber y decir en artes visuales, debe saberlo y decirlo mediante imágenes visuales); (b) la facilidad e inmediatez con la que gracias a la fotografía digital es posible obtener abundantes imágenes, correctamente enfocadas y expuestas, así como relativamente baratas, lo que permite concentrarse en los conceptos propiamente fotográficos y obtener algunas imágenes con suficiente calidad fotográfica; (c) porque la fotografía digital se ha convertido en el modo preeminente y característico de confección de imágenes en la sociedad actual y es conveniente que el profesorado conozca en profundidad cuáles son los modos predominantes de producción de imágenes visuales de la sociedad en la que vivimos.

Las imágenes fotográficas que se buscan deben responder fundamentalmente a tres preguntas, que corresponden a algunas de las principales competencias propias del aprendizaje artístico:

1. ¿Cuáles son las interrelaciones entre el cine clásico y las futuras maestras y maestros? o bien, expresada la pregunta de forma más directa y más abierta, ¿qué tienen que ver las imágenes de Buñuel con nosotros y con nuestra cotidianeidad profesional como docentes?

2. ¿Cómo reflexionar visualmente sobre las imágenes de la violencia y la educación? 

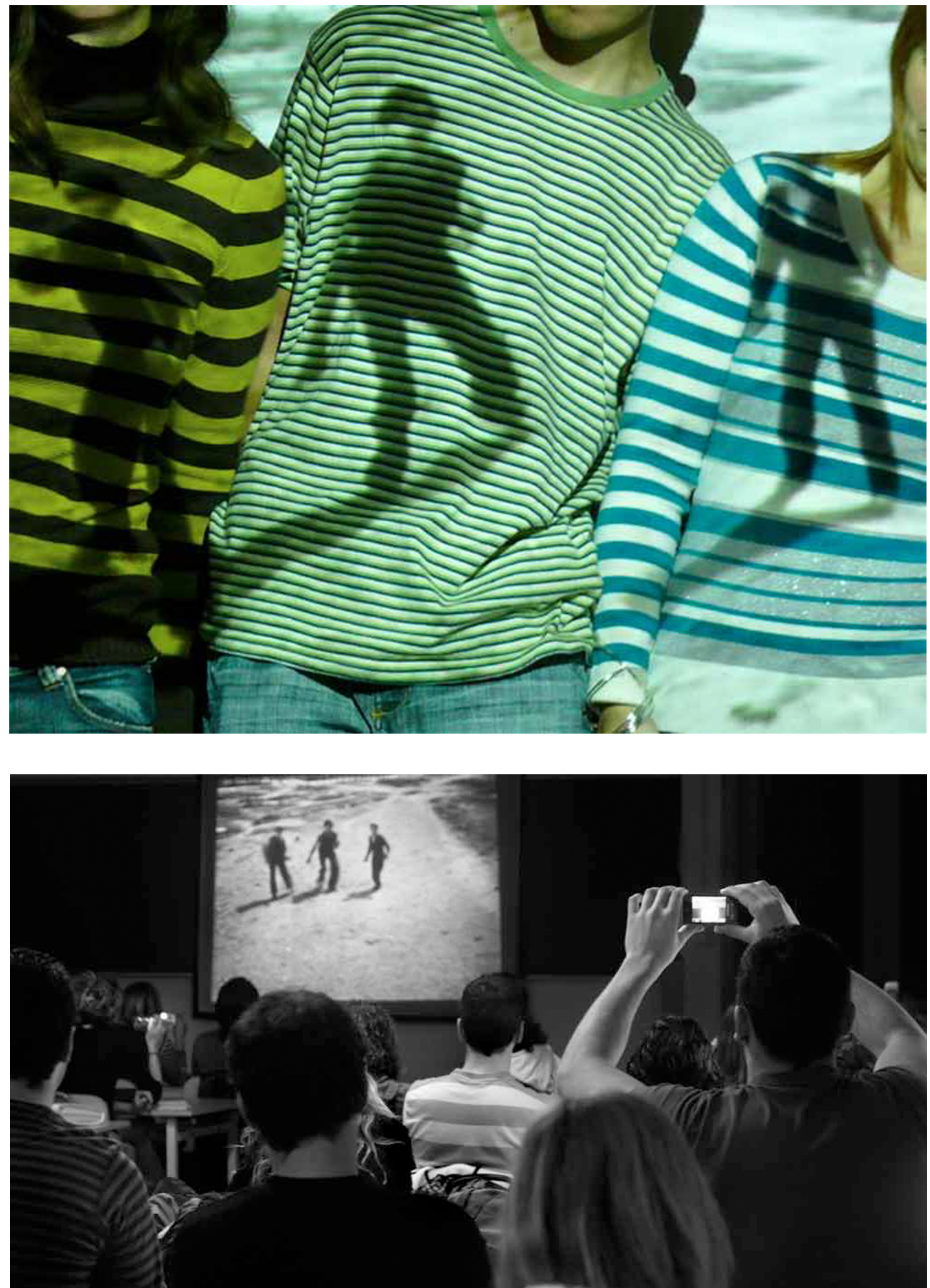

Fig.4. Autores. Aprendiendo de Buñuel IV (2012) Fotoensayo compuesto por dos fotografías digitales de los autores con una cita visual indirecta. (Dancigers \& Buñuel, 1950). 
3. ¿Qué podemos aprender el estilo foto-cinematográfico de Luis Buñuel para elaborar nuestras propias fotografías? Las imágenes que obtengamos no deberían ser las mismas si hubiésemos trabajado a partir de cualquier otro realizador. De forma semejante a como consideramos que entender una teoría o una obra de un autor/a implica ser capaz de usar los conceptos e ideas propios de esa teoría o autor/a de forma pertinente; de modo semejante en artes visuales consideramos que se ha entendido adecuadamente la obra de un artista cuando se es capaz de usar de forma pertinente sus conceptos e ideas visuales más relevantes en nuestras propias obras.

La secuencia de trabajo puede describirse a través de diez fases sucesivas. Las tres primeras corresponden al planteamiento del problema y a la búsqueda de información pertinente:

1. la fase inicial correspondió a la búsqueda y análisis de documentación sobre el movimiento surrealista, centrada en la pintura, el cine y la poesía, con especial hincapié en las figuras del poeta granadino Federico García Lorca y sus amigos Salvador Dalí y Luis Buñuel. Las imágenes del surrealismo (las primeras escenas del film Un chien andalou, por ejemplo) siguen manteniendo, a pesar del tiempo transcurrido y del uso sistemático que se ha hecho de sus descubrimientos visuales en el cine y la publicidad, un efecto turbador de gran eficacia para desterrar estereotipos visuales y para estimular muy poderosamente la libertad creadora. Todo ello debía conducir a un mayor deleite y mejor comprensión de la película Los Olvidados.

2. El visionado de la película completa se hace de forma individual, de modo semejante a como se estudia individualmente un texto escrito.

3. La tercera fase, que vuelve a ser en grupo, corresponde al análisis de obras fotográficas contemporáneas de gran relevancia que se construyen básicamente a partir de imágenes previas, tales como las de Cindy Sherman y las de Thomas Struth.

En estas tres primeras fases se trata de elaborar las preguntas iniciales, por un lado contextualizando la pieza cinematográfica de Buñuel a partir de la cual se desarrolla el traba- jo; y por otro, analizando las estrategias de algunos artistas contemporáneos para producir sus imágenes a partir de otras imágenes previas.

Los cinco pasos siguientes corresponden al diseño y producción de las imágenes.

4. La cuarta fase consiste en la selección de las escenas que se proyectarán en el aula y con las que se interactuará. Esta selección puede estar basada en diferentes criterios, según los objetivos de aprendizaje que nos propongamos. En esta ocasión escogimos tres secuencias de diferente duración: el apaleamiento de la gallina por parte del niño Pedro, que presenta a un grupo de niños pequeños, y la agresión al ciego.

5. La quinta fase es la proyección de las escenas seleccionadas en el aula, para que una parte del grupo interactúe con esas imágenes, mientras que el resto toma sus fotografías. Varias decisiones van a tener una gran repercusión en el resultado final: ¿a qué tamaño proyectar las imágenes para facilitar el entrelazamiento con nuestros cuerpos y sus sombras? ¿qué margen otorgar a la improvisación y al azar? ¿cómo combinar interacciones entre en pequeños grupos del alumnado o de una sola persona cuando en la escena aparecen uno o varios personajes? ¿conviene sumarse a las personajes cinematográficos en sus acciones o bien convertirse en sus víctimas?

6. La sexta fase consiste en recoger todas las fotografías que ha realizado el conjunto del grupo para clasificarlas en función de afinidades y semejanzas (varias personas del grupo habrán seleccionado encuadres muy semejantes entre sí) y para seleccionarlas según su calidad fotográfica.

7. La séptima fase consiste en presentar una selección de las imágenes obtenidas entre todos, al conjunto del grupo para su valoración colectiva. En esta fase se produce una situación de enorme interés educativo: el alumnado observa y analiza las imágenes que el propio grupo ha producido con el mismo interés y rigor con el que se trabajaron las imágenes realizadas por artistas de gran prestigio el la fase documental del proyecto.

8. La octava fase consiste en descubrir que el alumnado de la clase, que esta observando y analizando las imágenes en 

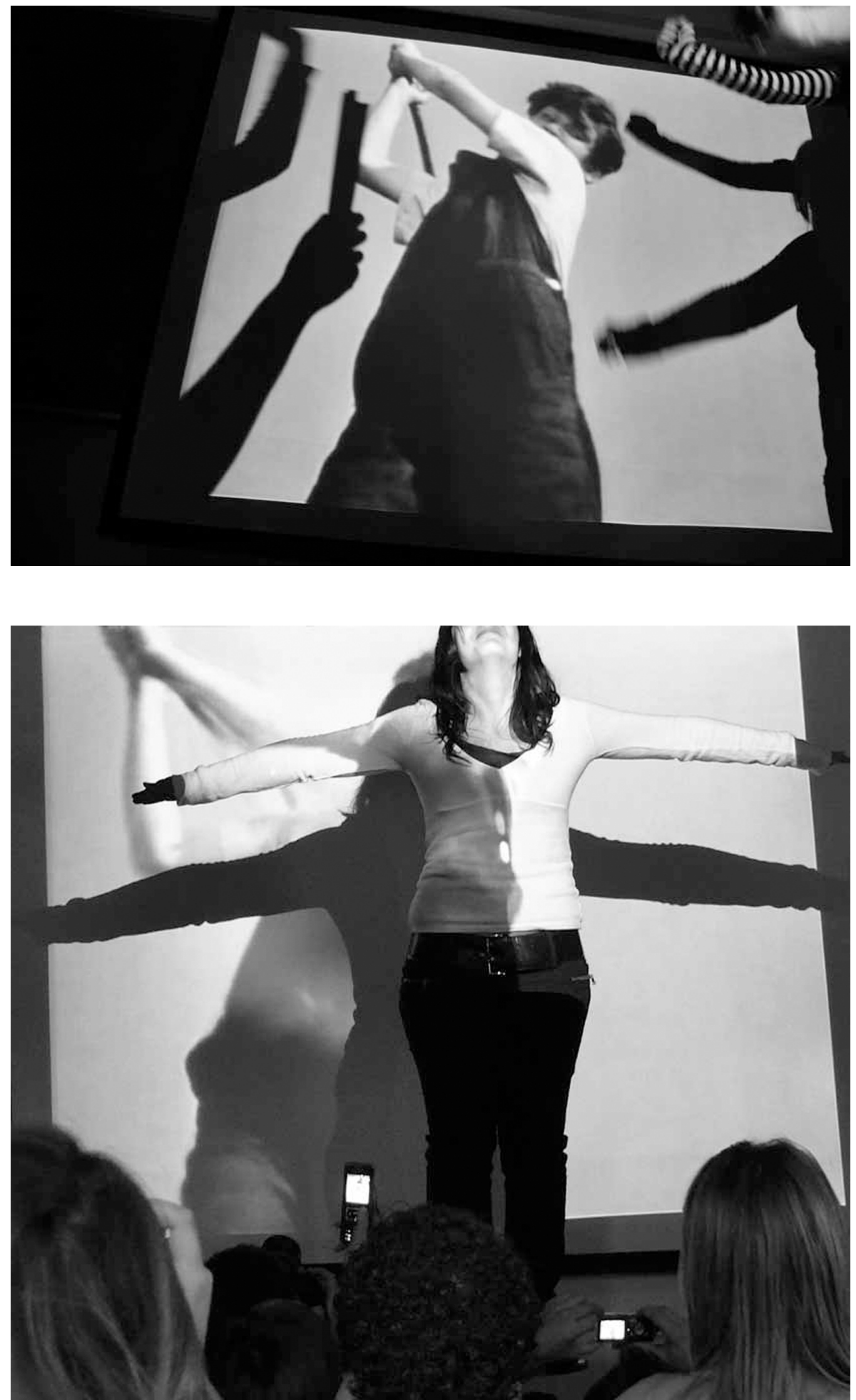

Fig.5. Autores. Aprendiendo de Buñuel V (2012) Fotoensayo compuesto por dos fotografías digitales de los autores con una cita visual indirecta. (Dancigers \& Buñuel, 1950). 
las que ellas y ellos mismos están interviniendo en los fotogramas de la película de Buñuel, constituyen un nueva escena que vale la pena seguir fotografiando, ya que ahora no solo podemos interactuar con los personajes de la película de Buñuel, sino también con nosotros mismos incorporados a la escena.

Los dos últimos pasos tienen un carácter más nítidamente investigador:

9. La novena fase consiste en la recopilación de toda la documentación, especialmente la fotográfica, del conjunto del proceso, su ordenación temática, su secuenciación narrativa, su selección y elaboración argumental.

10. La décima y última fase consiste en la preparación del resultado final: los fotoensayos definitivos.

\section{CONCLUSIONES}

Eisner, en varias de sus publicaciones iniciales sobre Investigación basada en las Artes, argumentó que de modo semejante a como en las décadas de los años setenta y ochenta del siglo XX la aparición y evolución de las metodologías cualitativas de investigación (frente a las cuantitativas) en educación y educación artística provocó un gran salto adelante en estos campos del conocimiento, el desarrollo actual de las Metodologías Artísticas podría lograr una nueva prosperidad investigadora en las primeras décadas del siglo XXI.

Tenemos la sensación que está concluyendo una primera fase de desarrollo de las Metodologías Artísticas de Investigación, en la que la tarea fundamental ha sido anunciar y lograr adhesiones a la buena nueva metodológica. Ahora se trataría de encarar la tarea de desarrollar técnicas e instrumentos de investigación artística específicos para cada modalidad artística adecuados para abordar eficazmente un amplio número de temas y situaciones.

\section{REFERENCIAS BIBLIOGRÁFICAS}

BANKS, M. (2001). Visual methods in social research. London: Sage. BARONE, T. \& Eisner, E. (2012). Arts based research. Los Angeles: Sage. BIGGS, M. \& Karlsson, H. (2011). The Routledge Companion to Research in the Arts. London: Routledge.
BRESLER, L. (ed.) (2007). International Handbook of Research in Arts Education. Dordrecht, The Netherlands: Springer.

BUÑUEL, L. (1982). Mi último suspiro. Barcelona: Plaza \& Janés.

CAHNMANN-TAYLOR, M. \& Siegesmund, R. (eds.) (2008). Arts-Based Research in Education. Foundations for Practice. New York: Routledge.

COHEN, L.; MANION, L. \& MORRISON, K. (2011). Research Methods in Education. New York : Routledge.

COLLIER, J. Jr. (1967). Visual anthropology: Photography as a research method. Holt, Rinehart \& Wilson: Nueva York.

DANCIGERS, O. (productor) \& Buñuel, L. (director). (1950). Los olvidados. Película cinematográfica. México: Ultramar Films. 88'.

DE LANGE, N.; MITCHelL, C. \& STUART, J. (eds.) (2007). Putting People in the Picture: Visual Methodologies for Social Change. Amsterdam: Sense.

DENZIN, N. K. \& LINCOLN, Y. S. (Eds.) (2000). Handbook of qualitative research. Thousand Oaks, CA: Sage.

DIAMOND, C. \& MULLEN, C (eds) (1999). The Postmodern Educator: Arts-based Inquiries and Teacher Development. Toronto: Peter Lang.

EISNER, E. (2008): Persistent tensions in arts-based research. En M. Cahnmann-Taylor, \& R. Siegesmund (eds.), Arts-Based Research in Education. Foundations for Practice. (16-27). New York: Routledge.

EISNER, E.W. \& DAY, M.D. (Eds.) (2004). Handbook of research and policy in art education. Mahwah, NJ: National Art Education Association \& Lawrence Erlbaum Associates.

GÓMEZ Muntané, M.C.; HERNÁNDEZ Hernández, F. \& PÉREZ López, H. J. (2006). Bases para un debate sobre investigación artística. Madrid: Ministerio de Educación y Ciencia.

HAMILTON, P. (ed), (2006). Visual research methods. London, Sage.

HANNULA, M.; SUORANTA J. \& VADÉN, T. (2005). Artistic Research. Theories, Methods, and Practices. Göteborg: Finland och Göteborgs universitet.

HICKMAN, R. (ed.) (2008). Research in Art \& Design Education. Issues and exemplars. Bristol, UK: Intellect.

IRWIN, R.; LEGGO, C. \& DE COSSON, A. (eds.) (2004). A/r/tography: Rendering self through arts-based living inquiry. Vancouver, British Columbia: Pacific Educational.

KELLY, A.; LESH, R. \& BAEK, J. (eds.) (2008). Handbook of design research methods in education : innovation in science, technology, engineering and mathematics learning and teaching. New York: Routledge.

KNOWLES, G. \& COLE, A. (2008). Handbook of the arts in qualitative research. Perspectives, methodologies, examples and issues. Thousand Oaks, CA: Sage.

KNOWLES, G.; LUCIANI, T.; COLE, A. \& NEILSEN, L. (2007). The art of visual inquiry. Halifax: Backalong Books.

KNOWLES, C.\& SWEETMAN, P. (eds.) (2004). Picturing the Social Landscape: Visual Methods and the Sociological Imagination. London: Routledge.

LEAVY, P. (2009). Method meets art: Arts-based research practices. New York: Guildford. 
LAPIERRE, S. \& ZIMMERMAN, E. (Eds.) (1997). Research methods and methodology for art education. Reston, VA: National Art Education Association.

MÄKELÄ, M. \& ROUTARINNE, S. (eds.) (2006). The art of research. Research practices in art and design. Helsinki: University of art and design.

MARÍN-VIADEL, R. (ed.) (2005). Investigación en Educación artística: Temas, métodos y técnicas de indagación, sobre el aprendizaje y la enseñanza de las artes y culturas visuales. Granada: Universidad de Granada y Universidad de Sevilla.

MARÍN-VIADEL, R. (2011). Las investigaciones en educación artística y las metodologías artísticas de investigación en educación: temas, tendencias y miradas. Educação, 34, (3), 271-285.

http://revistaseletronicas.pucrs.br/ojs/index.php/faced/article/viewFile/9515/6776

MARÍN-VIADEL, R.; LAIGLESIA GONZÁLEZ DE PEREDO, J.F. \& TOLOSA Marín, J.L. (1998). La Investigación en Bellas Artes. Tres aproximaciones a un debate. Granada: Grupo Editorial Universitario.

MARÍN-VIADEL, R. \& ROLDÁN, J. (2008). Imágenes de las miradas en el museo. Un fotoensayo descriptivo-interpretativo a partir de $\mathrm{H}$. Daumier. En R. Huerta \& R. de la Calle (eds.) Mentes sensibles. Investigar en educación y en museos. (97-108). Valencia: Universidad de Valencia.

MARÍN-VIADEL, R. \& ROLDÁN, J. (2010). Photo essays and photographs in visual arts based educational research. International Journal of Education through Art. 6 (1), 7-23. doi: 10.1386/eta.6.1.7_1

MARIN-VIADEL, R. \& ROLDÁN, J. (2011). Descripción visual de las Metodologías Artísticas de Investigción: ver (literalmente) los problemas (educativos). En J. Vallés Villanueva; M.D. Álvarez \& R. Rickemann Del Castillo (eds.) L'activitat del docent: Intervenció, investigació, innovació. (151-170). Girona: Ed. Documenta Universitaria.

MARTín CUETO, M. (2008). Palabras-fotos. Un ensayo visual sobre imágenes y educación a partir de fotografías realizadas por niños y niñas de tercero de Educación Infantil. Kíkiriki. Cooperación educativa. 90, 69-73. Kíkiriki. Cooperación educativa. 90, 69-73.

MENA DE TORRES, J. (2010) Representaciones visuales de la educación: la construcción del concepto de educación a través de las imágenes de la fotografía artística y el alumnado. (CD). En Actas del 3 o Congreso Internacional de Educación Artística y Visual: Pensamiento crítico y globalización. Málaga: Universidad de Málaga. 8-10 Abril 2010.

MCNIFF, S. (1998). Art-based Research. London: Jessica Kingsley.

MOLINET MEDINA, X. (2010) El retrato fotográfico como estrategia educativa. Experiencias a partir de Richard Avedon, In the American West (CD). En Actas del 3o Congreso Internacional de Educación Artística y Visual: Pensamiento crítico y globalización. Málaga: Universidad de Málaga. 8-10 Abril 2010.

PÉREZ CUESTA, G. \& Mena de Torres, J. (2010). Los procesos y la experiencia artística como instrumento para la indagación en el arte. El mundo creativo de Luis Gordillo como modelo educativo en el Museo Caja GRANADA-Memoria de Andalucía. Actas del 1ํ Congreso Internacional de Arte, Ilustración y Cultura visual en Educación Infantil, Primaria: construcción de identidades. 3-6 Noviembre 2010. Granada: Universidad de Granada.
PINK, S. (2001). Doing visual ethnography: Images, media, and representation in research. London: Sage.

PROSSER, J. (Ed.) (1998). Image Based Research: A Sourcebook for Qualitative Researchers. Londres: Falmer.

ROLDÁN, J. (coord.) (2007). Diálogos de imágenes. Creación artística en papel. Granada: Universidad de Granada.

ROLDÁN, J. (2008). Modelos de continuidad en fotodiálogos. (CD). En Actas del 2 - Congreso Internacional de Educación Artística y Visual: Retos sociales y diversidad cultural. Sevilla: Ilustre Colegio Oficial de Licenciados y Doctores en Bellas Artes de Andalucía. 20-22 Abr. 2006.

ROLDÁN, J. (2011). El mercado de la caridad: Las imágenes fotográficas de la infancia en la publicidad (solidaria) de las ONGDs. En R. Marín-Viadel, (ed.) Infancia, Mercado y Educación. (141-158). Archidona: Aljibe.

ROLDÁN, J. \& Hernández, M. (coords) (2010). Al otro lado. Fotografía y pensamiento visual en las culturas universitarias. Aguascalientes: Universidad de Aguascalientes.

ROLDÁN, J. y Marín-Viadel, R. (2012). Metodologías Artísticas de Investigación en Educación. Archidona: Aljibe.

ROLDÁN RAMíREZ, J.; y Marín Viadel, R. (2009). Proyecciones, tatuajes y otras intervenciones en las obras del museo. (Un fotoensayo a partir de T. Struth). Arte, Individuo y Sociedad. 21, 99-106.

www.ucm.es/BUCM/revistasBUC/portal/mo-

dules.php?name=Revistas $2 \&$ id $=$ ARIS

ROSE, G. (2007). Visual Methodologies. An introduction to the interpretation of visual materials. London, Sage.

SPRINGGAY, S.; Irwin, R. L.; Gouzouasis, P. (Eds.). (2008). Being with a/r/ tography. Rotterdam: Sense.

STANCZAK, G. C. (2007). Visual Research Methods. Image, Society, and Representation. London: Sage.

SULLIVAN, G. (2010). Art practice as research: Inquiry in the Visual Arts. Thousand Oaks, CA: Sage.

VARTO, J. (2009). Basics of artistic research. Ontological, epistemological and historical justifications. University of art and design. Helsinki. 


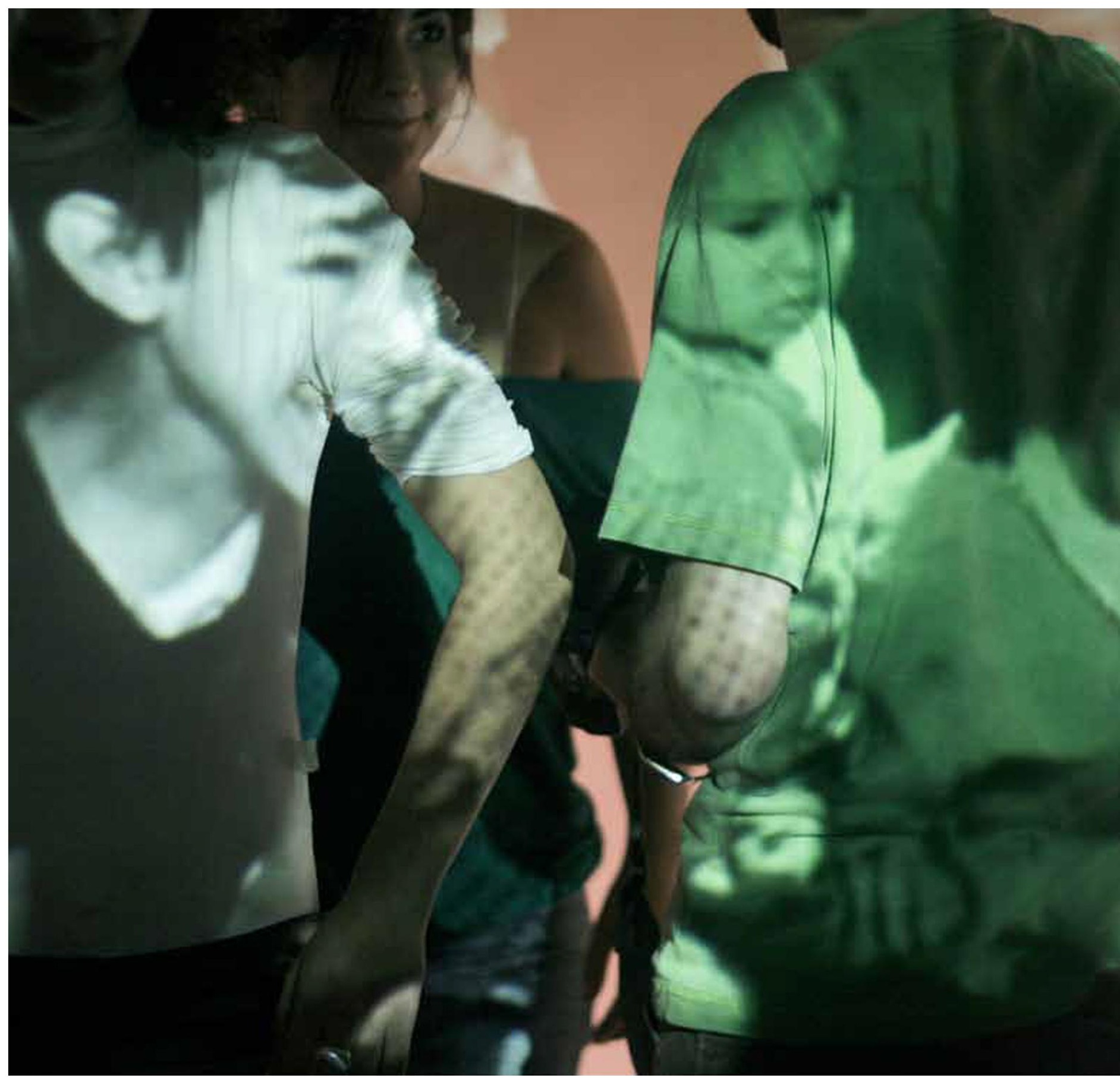

Fig.6. Foto-Conclusión. Autores. Aprendiendo de Buñuel VI (2012) Fotoensayo compuesto por dos fotografías digitales de los autores con una cita visual indirecta. (Dancigers \& Buñuel, 1950). 


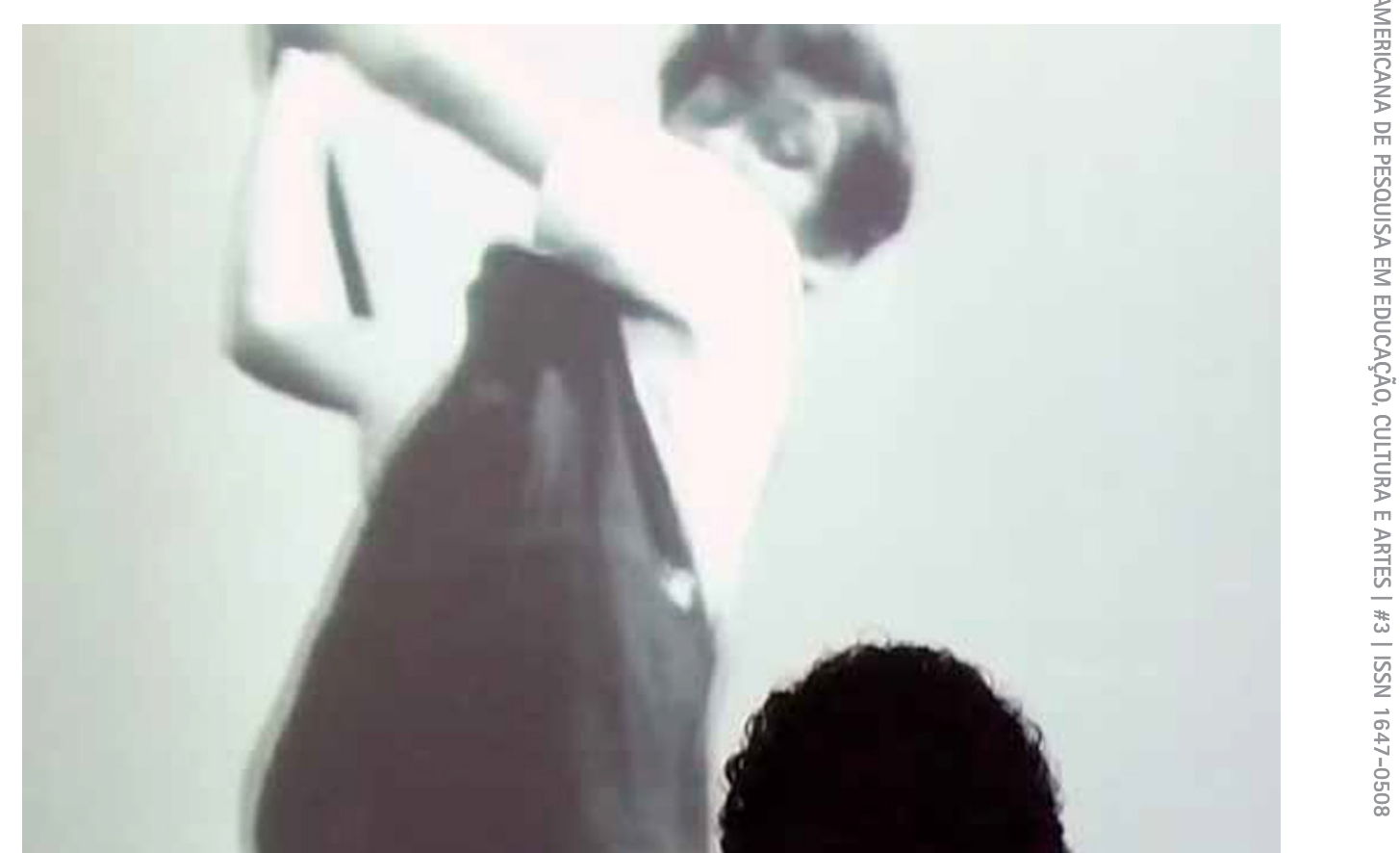

